\title{
Is the fluoride intake by diet and toothpaste in children living in tropical semi-arid city safe?
}

Priscila Ferreira Torres de OLIVEIRA ${ }^{(a)}$ Jaime Aparecido CURY(b)

Carolina Veloso LIMA ${ }^{(a)}$

Glauber Campos VALE(c)

Marina de Deus Moura de LIMA(a)

Lúcia de Fátima Almeida de Deus MOURA $^{(a)}$

Marcoeli Silva de MOURA ${ }^{(a)}$

(a) Universidade Federal do Piauí - UFPI, Department of Pathology and Dental Clinics, Teresina, Pl, Brazil.

(b) Universidade Estadual de Campinas Unicamp, Faculty of Dentistry of Piracicaba, Piracicaba, SP, Brazil.

(c) Universidade Federal do Piauí - UFPI, Restorative Dentistry Department, Teresina, PI, Brazil.
Declaration of Interests: The authors certify that they have no commercial or associative interest that represents a conflict of interest in connection with the manuscript.

\section{Corresponding Author:}

Marcoeli Silva de Moura

E-mail: marcoeli-moura@uol.com.br

htpps://doi.org/10.1590/1807-3107bor-2018.vol32.0026

Submitted: October 16, 2017

Accepted for publication: January 21, 2018

Last revision: February 23, 2018
Abstract: Data about total fluoride intake in children living in a tropical semi-arid climate city is scarce, thus we conducted this study. Fifty-eight children aged two to five years, living in a Brazilian tropical city with optimally fluoridated water were selected. Dietary samples were collected using the duplicate diet method on two non-consecutive days in the children's home. Water was collected separately from the other drinks. The intake from toothpaste was determined by subtracting the amount of fluoride recovered after brushing from the amount placed on the toothbrush. The mean total dose (SD) of fluoride intake was $0.043(0.016) \mathrm{mg} \mathrm{F} \mathrm{kg}^{-1} \mathrm{~d}^{-1}$, with the major $(60.6 \%)$ contribution from water. The factors associated with the ingestion of fluoride from toothpaste were fluoride concentration of the toothpaste $(p=0.03)$ and the use of kids toothpaste $(p=0.02)$. The findings suggest that children have a low fluoride intake, measured by at-home meals and use of fluoride toothpaste; drinking water is the main source of fluoride ingestion.

Keywords: Fluorides; Fluorosis, Dental; Toothpastes; Diet.

\section{Introduction}

In recent decades, there has been a decline in the worldwide prevalence of dental caries in the population, which is associated with the use of fluorides. ${ }^{1}$ Fluoridation of the public water supply and the use of fluoride toothpastes are the most important methods of fluoride delivery. ${ }^{2,3}$ However, an increase in the prevalence of dental fluorosis due to the intake of multiple sources of fluoride during tooth formation has been observed. ${ }^{4}$ Burt ${ }^{5}$ empirically determined a fluoride intake dose considered safe: from 0.05 to $0.07 \mathrm{mg} \mathrm{F} / \mathrm{kg}$ body weight/day.

Some studies showed that children's fluoride intake from diet (solid and liquid) in a subtropical region of Brazil with fluoridated water was not relevant, with doses of approximately $0.04 \mathrm{mg} \mathrm{F} / \mathrm{kg}$ body weight/day. ${ }^{6,7}$ However, Lima and Cury ${ }^{7}$ reported that the amount of fluoride ingested during the hot season was $19 \%$ higher than during the cold season. Such data can be troubling for people living in tropical climate regions, because they tend to consume more water than people from cooler regions. In addition, children are at risk of ingesting fluoride from other sources, such as toothpaste.

Previous studies have evaluated the dose of fluoride intake by children from tropical semi-arid climates. ${ }^{8,9,10}$ Omena et al. ${ }^{8}$ evaluated fluoride intake from drinking water and from fluoride toothpaste, without considering 
others sources of fluoride intake (others liquids and food). Buzalaf et. al. ${ }^{9}$ reported fluoride intake from the entire diet (water, other beverages and solid foods) and fluoride toothpaste in a city with naturally fluoridated water. In addition, Lima et al. ${ }^{10}$ evaluated fluoride intake from diet (liquid and solid foods) and fluoride toothpaste in a city with artificially fluoridated water; however, the authors reported a low intake of water maybe because children spent most of their time in the classroom. Furthermore, another study developed in a city with tropical semi-arid climate found an increase in cases of dental fluorosis with esthetically undesirable appearance. ${ }^{11}$

Aiming to expand the existing knowledge, this study was developed in a city with tropical semiarid climate to determine the total daily dose of fluoride intake from diet (water, other beverages and solid diet, collected at children's home) and from use of fluoride toothpaste in children living in a city with optimally fluoridated water and with high temperatures throughout the year.

\section{Methodology}

This study was approved by the Ethics Committee of the Federal University of Piauí (Opinion 667,541), according to the guidelines of Declaration of Helsinki.

Teresina, Piauí, is a Northeastern Brazilian city with a tropical climate and average annual maximum temperatures above $33.5^{\circ} \mathrm{C}$ observed over the last 10 years. The public water supply has been fluoridated since 1978 in accordance with the Brazilian legislation (optimal recommended concentration of $0.7 \mathrm{mg} / \mathrm{L}$, ranging from 0.6 to $0.8 \mathrm{mg} / \mathrm{L}$ for locations with average maximum temperatures of 26.7 to $32.5^{\circ} \mathrm{C}$ ). ${ }^{12}$

Children were selected from a private school (convenience sample), living in Teresina, aged between two and five years, which is considered the critical period for the development of fluorosis in aesthetically important teeth. $13,14,15$

For sample size calculation, we used the formula $\mathrm{n}=2 \mathrm{~s}^{2}(\mathrm{ta} / 2+\mathrm{t} \beta)^{2} / \mathrm{d}^{2}$, where "s" is the estimated variation of fluoride intake ( $\mathrm{s}=0.2) ;$; $\mathrm{ta} / 2$ " is the value of the $t$ distribution to $95 \%$; " $t \beta$ " is the power of the test $(\mathrm{t} \beta=20 \%)$ and " $\mathrm{d}$ " is the difference to be detected in the fluoride intake $(\mathrm{d}=0.1){ }^{16}$ Thus, the minimum sample size required was 62 children. Considering the possibility of losses during the study, $30 \%$ was added to the minimum value, to give a total of 81 children.

Children were included in the study if they regularly consumed water from the fluoridated public water supply, used fluoride toothpaste, and whose caregivers signed the consent form. Children were ineligible for the study if they had any acute or chronic infection or were taking any medicine or fluoride supplement.

Details of the research were explained to the children's caregivers. A questionnaire about demographic data (age, gender, and mother education level), eating habits (food diary of the collection day), and oral hygiene (brushing frequency, who performs the brushing, type of toothpaste, and amount of toothpaste used) was sent to the caregivers. Samples were collected from May to August 2014. All children were weighed on each day of diet collection (twice), on a digital scale (Dayhome Comercial LTDA, São Paulo, Brazil) to determine the fluoride dosage ( $\mathrm{mg} \mathrm{F} / \mathrm{kg}$ body weight).

Fluoride intake was determined by the duplicate diet method, as described by Guha-Chowdhury et al. ${ }^{17}$ but with a modification, because the collection was made at home and held over two days, separated by an interval of two months. Solid food, water, and other beverages were collected in plastic bottles and packed separately. Solid foods included rice, bread, beans, soup, meat, biscuits, fruit, vegetables, and pasta, among others. Other beverages included juice, yogurt, milk, coffee, and soda. The food was collected and placed in a refrigerator by the parents, on a day when both the child and the parent were home.

The samples were homogenized in laboratory. The weight of solids and the volume of liquids were recorded for the analysis of fluoride. Deionized water was added to the solid foods and homogenized with a blender. The other beverages were also homogenized using a blender. Aliquots of $15 \mathrm{~mL}$ of solid food, water, and other beverages were stored in a plastic container at $-4^{\circ} \mathrm{C}$ for further analysis.

The fluoride obtained from diet samples was extracted using the microdiffusion technique facilitated by hexamethyldisiloxane (HMDS). ${ }^{18}$ The fluoride analyses were performed using a fluoride ion-specific electrode (Orion Model 96-09, Orion 
Research Incorporated, Cambridge, MA, USA) and an ion analyzer (Orion Star A211), previously calibrated with standard solutions $(0.0156 \pm 2.0 \mathrm{mg} \mathrm{F} / \mathrm{mL})$ under the same conditions as the samples. All diet samples were analyzed in triplicate. To calculate the daily dose, an average of the two sampling days was calculated.

The fluoride intake from toothpaste was determined by subtracting the amount of fluoride recovered after brushing from the amount placed on the toothbrush, ${ }^{17}$ as collected during a brushing session on the second day of diet collection. It was recommended for children to perform their habitual brushing routine, using their own toothpaste and toothbrush. The researcher supervised and observed how the brushing was performed. Deionized water was provided to assist in brushing and in washing the brush. Saliva and deionized water were used to rinse the mouth and toothbrush after brushing, and the liquid was collected in a plastic cup. These brushing residues were homogenized, the volume recorded, and a 15 $\mathrm{mL}$ aliquot stored at $-4^{\circ} \mathrm{C}$ for further analysis. The toothpastes of all children were collected for analysis of total fluoride and total soluble fluoride (TSF).

Samples were centrifuged $(3,000 \mathrm{~g}, 10 \mathrm{~min})$ and the TSF in the supernatant was determined, after performing $2 \mathrm{M} \mathrm{HCl}$ hydrolysis, neutralization with $1 \mathrm{M} \mathrm{NaOH}$ and buffering with TISAB II. Fluoride analyses were performed using a specific fluoride ion electrode (Orion Model 96-09, Orion Research Incorporated, Cambridge, USA) and an ion analyzer (Orion Star A211), previously calibrated with standard solutions ( 0.125 to $32 \mathrm{ug} \mathrm{F} / \mathrm{ml})$ under the same conditions as the samples. All samples were analyzed in duplicate. The TSF present in the toothpastes was determined; values used in the calculations accounted only for the bioavailable fluoride. ${ }^{6,19,20}$ If the total fluoride present in toothpastes was considered, the ingested dose could be overestimated. ${ }^{21}$ The daily brushing frequency and weight of the child were used to determine fluoride intake.

The maximum daily average temperatures $\left({ }^{\circ} \mathrm{C}\right)$ from May to August were provided by the National Institute of Meteorology - INMET (Source: INMET Network Data). Tap water samples were collected from the residence of each child on the days of diet collection for fluoride analysis.
A descriptive analysis was conducted using onedimensional contingency tables. The chi-square test for equality of proportions and basic statistics for the analysis of numerical variables were used. In order to evaluate the associations between measures, Pearson correlation coefficients were calculated, twodimensional contingency tables were constructed and the V Cramer coefficient was adopted to quantify the association. The chi-square test was used to determine the p-value for the likelihood ratio (G2). Repeated measures analysis of variance based on generalized linear mixed models was used to compare the means of fluoride intake from different sources. The calculations were performed using the SAS system and all statistical tests adopted a significance level of $5 \%(\alpha=0.05)$.

\section{Results}

Of the 81 children whose parents agreed to participate in the study, 13 were not included in the sample because diet collection was not performed. After analysis of the water used at home, 10 children were excluded as they drank mineral bottled water without fluoride. Thus, the final sample consisted of 58 children (36 girls and 22 boys) with a mean age of $49.8( \pm 11.9)$ months and an average weight of $17.9( \pm 3.6) \mathrm{kg}$.

The average fluoride concentration in tap water was $0.6( \pm 0.1) \mathrm{mg} \mathrm{F} / \mathrm{l}$, which is the lower limit according to Brazilian regulations. The average maximum temperature during the days of sample collection was $33.5 \pm 1.1^{\circ} \mathrm{C}$.

Fluoride intake by children is described in Table 1. The largest contribution was from water $(60.6 \%$ of the total diet).

The total average fluoride intake from diet and toothpaste was low. However, $12.1 \%$ of study participants exceeded the upper threshold of $0.07 \mathrm{mg}$ $\mathrm{F} \cdot \mathrm{kg}^{-1} \mathrm{~d}^{-1}$ for being at risk of esthetically undesirable fluorosis, and $29.3 \%$ of children reached the lower

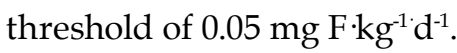

Most children used flavored kids toothpastes that contain $\mathrm{NaF}$ and silica for abrasiveness (72.41\%). Toothpastes containing 1,100 ppm F were the most frequent (Table 2). 
Is the fluoride intake by diet and toothpaste in children living in tropical semi-arid city safe?

Table 1. Contribution of each source of fluoride to total fluoride intake $\left(\mathrm{mg} \mathrm{F} \times \mathrm{kg}^{-1} \times \mathrm{d}^{-1}\right)$ for children from diet and fluoride toothpaste.

\begin{tabular}{|c|c|c|c|c|}
\hline Measure & Mean & Standard deviation & Minimum & Maximum \\
\hline \multicolumn{5}{|l|}{ Intake from diet } \\
\hline Water & 0.021 & 0.009 & 0.007 & 0.043 \\
\hline Other drinks & 0.009 & 0.008 & 0.001 & 0.040 \\
\hline Solid diet & 0.005 & 0.004 & 0.001 & 0.022 \\
\hline Total Dose from diet & 0.033 & 0.013 & 0.011 & 0.073 \\
\hline \multicolumn{5}{|c|}{ Variables related to the use of fluoridated toothpaste } \\
\hline $\mathrm{TSF}^{*}(\mu \mathrm{g} \mathrm{F} / \mathrm{mg})$ & 1065.684 & 171.520 & 518.400 & 1440.200 \\
\hline Amount of toothpaste (g) & 0.305 & 0.272 & 0.010 & 1.040 \\
\hline Brushing time $(\mathrm{s})$ & 95.862 & 40.266 & 21.000 & 255.000 \\
\hline Fluoride intake from brushing (\%) & 27.032 & 19.159 & 0.000 & 74.300 \\
\hline Fluoride from toothpaste ingestion & 0.010 & 0.010 & 0 & 0.043 \\
\hline \multicolumn{5}{|l|}{ Total fluoride intake } \\
\hline Diet + Toothpaste & 0.043 & 0.016 & 0.011 & 0.083 \\
\hline
\end{tabular}

*TSF: Total soluble fluoride.

Table 2. Toothpastes characteristics used in the sample and chi-square test for equal proportions between the variables.

\begin{tabular}{lcccc}
\hline \multirow{2}{*}{ Variables } & \multicolumn{2}{c}{ Characteristics } & \multicolumn{2}{c}{ Chi-square test } \\
\cline { 2 - 5 } & Frequency & Percentage & Statistic $\chi^{2}$ & p-value \\
\hline Type of toothpaste & & & & \\
Adult & 13 & 22.41 & 17.65 & 0.0001 \\
Child & 45 & 77.59 & & \\
Type of fluoride & & & & \\
MFP* & 16 & 27.59 & 11.65 & 0.0006 \\
NaF** & 42 & 72.41 & & \\
Abrasive & & & & \\
Calcium & 12 & 20.69 & 19.93 & 0.0001 \\
carbonate & 46 & 79.31 & & \\
Silica & 3 & 5.17 & & \\
Fluoride concentration (Mg F/mg) & & & \\
500 & 3 & 3.45 & & \\
750 & 2 & 67.24 & 115.79 & 0.0001 \\
1,100 & 39 & 1.72 & & \\
1,350 & 1 & 20.69 & & \\
1,450 & 12 & 1.72 & & \\
1,500 & 1 & & & \\
\hline MFP: Sodium monofluorophosphate; & $* *$ NaF: Sodium fluoride.
\end{tabular}

Table 3 describes the brushing habits of children. Most children had their teeth brushed by their mother, 2 to 3 times per day and with $1 / 4$ of the brush covered with toothpaste.
The fluoride intake from toothpaste was divided into three categories: < 0.0001 , from 0.0001 to 0.0025

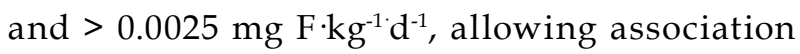
analyses between this source of fluoride intake and the variables related to brushing (Table 4). Higher amounts of fluoride were ingested with the use of 1,100 ppm $\mathrm{F}$ toothpastes $(\mathrm{p}=0.0384)$ and kids toothpastes $(p=0.0209)$.

Fluoride intake from water was significantly higher than from all other sources (Figure). Additionally, the intake of fluoride from toothpaste was significantly higher than from solid diet.

\section{Discussion}

According to the average fluoride intake, children in this study were exposed to safe levels concerning the risk of dental fluorosis. Fluoride exposure obtained in this study was lower than the that obtained in other studies conducted in Northeastern Brazil, ${ }^{8,910,22}$ which can be explained by the small amount of toothpaste used for brushing and consequent reduction of fluoride intake from toothpaste. In addition, Teresina has the minimum recommended concentration of fluoride in the public water supply.

Comparing dietary fluoride ingestion in this study with those of others conducted in tropical 
Table 3. Brushing characteristics of the sample.

\begin{tabular}{|c|c|c|c|c|}
\hline \multirow{2}{*}{ Variables } & \multicolumn{2}{|c|}{ Characteristics } & \multicolumn{2}{|c|}{ Chi-square test } \\
\hline & Frequency & Percentage & Statistic $\chi^{2}$ & $\mathrm{p}$-value \\
\hline \multicolumn{5}{|l|}{ Brushing frequency (daily) } \\
\hline 1 & 1 & 1.72 & \multirow{4}{*}{50.41} & \multirow{4}{*}{0.0001} \\
\hline 2 & 29 & 50.00 & & \\
\hline 3 & 27 & 46.55 & & \\
\hline 4 & 1 & 1.72 & & \\
\hline \multicolumn{5}{|l|}{ Amount of toothpaste } \\
\hline $1 / 4$ brush & 30 & 51.72 & \multirow{3}{*}{8.93} & \multirow{3}{*}{0.0115} \\
\hline Brush Half & 15 & 25.86 & & \\
\hline The entire brush & 13 & 22.41 & & \\
\hline \multicolumn{5}{|l|}{ Act of wetting the brush } \\
\hline Yes & 35 & 60.34 & \multirow{2}{*}{2.48} & \multirow{2}{*}{0.1151} \\
\hline No & 23 & 39.66 & & \\
\hline \multicolumn{5}{|l|}{ Brushing technique } \\
\hline Horizontal & 44 & 75.86 & \multirow{3}{*}{47.62} & \multirow{3}{*}{0.0001} \\
\hline Vertical & 5 & 8.62 & & \\
\hline Fones & 9 & 15.52 & & \\
\hline \multicolumn{5}{|l|}{ Position brushing } \\
\hline Facing the child & 34 & 68.00 & \multirow{3}{*}{32.92} & \multirow{3}{*}{0.0001} \\
\hline Child on her lap & 1 & 2.00 & & \\
\hline Starkey (adult behind the child) & 15 & 30.00 & & \\
\hline \multicolumn{5}{|l|}{ Who was brushing } \\
\hline Mother & 34 & 58.62 & \multirow{5}{*}{62.17} & \multirow{5}{*}{0.0001} \\
\hline Father & 1 & 1.72 & & \\
\hline Nanny & 13 & 22.41 & & \\
\hline Other caregiver & 2 & 3.45 & & \\
\hline Child & 8 & 13.79 & & \\
\hline
\end{tabular}

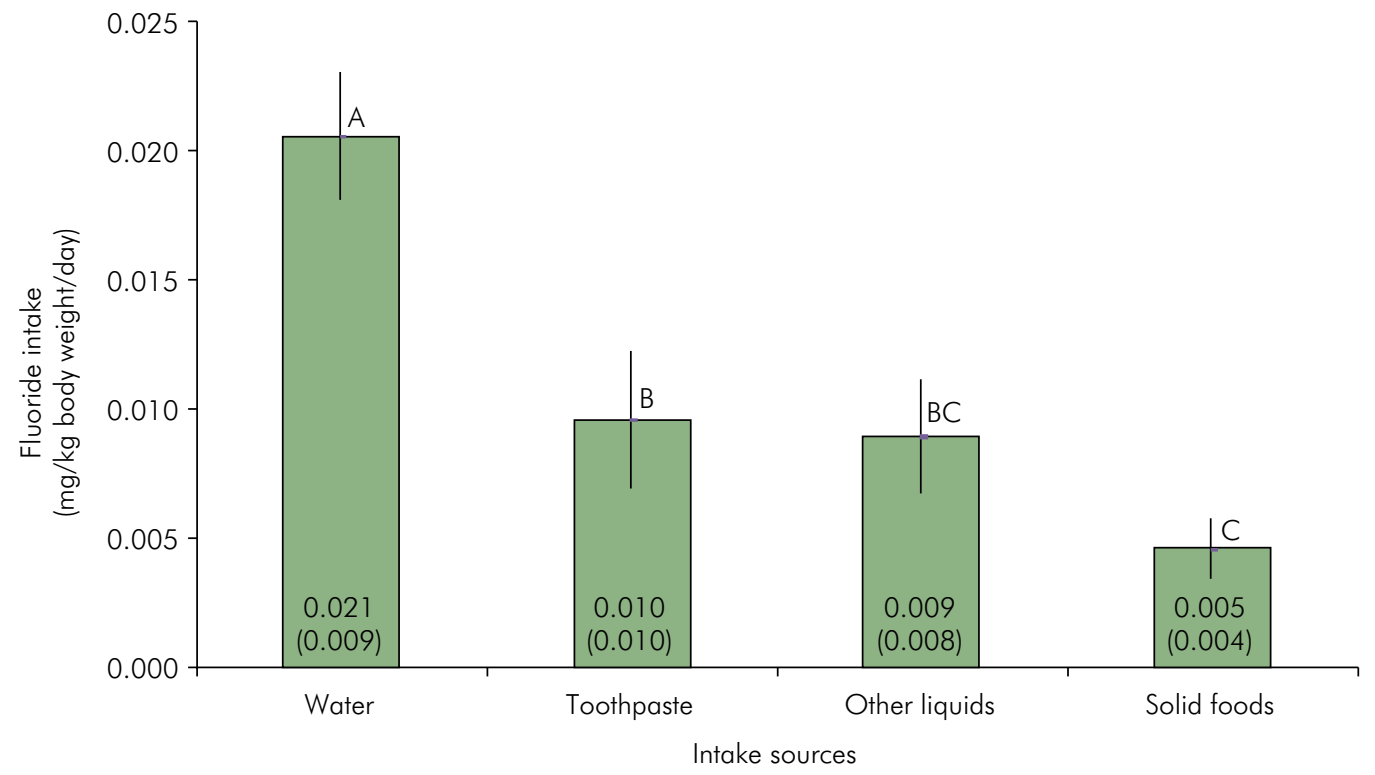

Figure. Mean (SD), confidence intervals (95\%), and Tukey's post test to compare the fluoride intake. Bars with the same letter are not significant $(p>0.05)$. 
Table 4. Frequency (percentage), statistical $\vee$ Cramer and $p$-value of the chi-square likelihood ratio $(G 2)$ to assess the associations between the amount of ingested fluoride and the variables related to brushing.

\begin{tabular}{|c|c|c|c|}
\hline \multirow{2}{*}{$\begin{array}{l}\text { Brushing-related } \\
\text { variables }\end{array}$} & \multicolumn{3}{|c|}{$\begin{array}{l}\text { Ingested fluoride from toothpaste } \\
\left(\mathrm{mg}^{\mathrm{kg}}{ }^{-1} \cdot \mathrm{day}^{-1}\right)\end{array}$} \\
\hline & $(<0.0001)$ & $(0.0001-0.0025)$ & $(>0.0025)$ \\
\hline \multicolumn{4}{|c|}{$\begin{array}{l}\text { Fluoride concentration in toothpaste (mg F/mg F) (V: } 0.2908- \\
\text { p-value: } 0.0384)\end{array}$} \\
\hline $500-750$ & $2(40.00)$ & $3(60.00)$ & $0(0.00)$ \\
\hline 1,100 & $4(10.53)$ & $30(7.95)$ & $4(10.53)$ \\
\hline $1,350-1,500$ & $6(46.15)$ & 7 (53.85) & $0(0.00)$ \\
\hline \multicolumn{4}{|c|}{ Type of toothpaste (V: 0.3754 - p-value: 0.0209) } \\
\hline Adult & $6(50.00)$ & $6(50.00)$ & $0(0.00)$ \\
\hline Child & $6(13.64)$ & $34(77.27)$ & 4 (9.09) \\
\hline \multicolumn{4}{|c|}{ Type of fluoride (V: 0.1782 - p-value: 0.2569$)$} \\
\hline MFP* & $4(28.57)$ & $10(71.43)$ & $0(0.00)$ \\
\hline $\mathrm{NaF}^{* *}$ & $8(19.05)$ & $30(71.43)$ & $4(9.52)$ \\
\hline \multicolumn{4}{|c|}{ Abrasive (V: 0.2121 - p-value: 0,2110$)$} \\
\hline $\begin{array}{l}\text { Calcium } \\
\text { carbonate }\end{array}$ & $4(36.36)$ & $7(63.64)$ & $0 \quad(0.00)$ \\
\hline Silica & $8(17.78)$ & $33(7.33)$ & $4 \quad(8.89)$ \\
\hline \multicolumn{4}{|c|}{ Brushing frequency (V: 0.0515 - p-value: 0.9282$)$} \\
\hline 1 a 2 & 7 (23.33) & $21(70.00)$ & $2(6.67)$ \\
\hline 3 a 4 & $5(19.23)$ & $19(73.08)$ & $2(7.69)$ \\
\hline \multicolumn{4}{|c|}{ Wetting the brush (V: $0.2824-p$-value: 0.0546$)$} \\
\hline Sim & $5(14.71)$ & $25(73.53)$ & $4(11.76)$ \\
\hline Não & $7(31.82)$ & $15(68.18)$ & $0(0.00)$ \\
\hline \multicolumn{4}{|c|}{ Person performing (V: 0.3513 - p-value: 0.0672$)$} \\
\hline Mother & $9(27.27)$ & 24 (72.73) & $0(0.00)$ \\
\hline Father & $\begin{array}{c}1 \\
(100.00)\end{array}$ & $0(0.00)$ & $0(0.00)$ \\
\hline Nanny & 1 (8.33) & $9(7.00)$ & $2(16.67)$ \\
\hline Other caregiver & $0(0.00)$ & $2(100.00)$ & $0(0.00)$ \\
\hline Child & $1(1.50)$ & $5(62.50)$ & $2(25.00)$ \\
\hline
\end{tabular}

*MFP: Sodium monofluorophosphate; ${ }^{* *}$ NaF: Sodium fluoride.

cities, such as in Rodrigues et al., ${ }^{22}$ we found lower values. Fluoride intake from drinks in this study was $0.03 \mathrm{mg} \mathrm{F} \mathrm{kg}^{-1} \mathrm{~d}^{-1}$, which is higher than the dose observed by Lima et al. ${ }^{10}\left(0.025 \mathrm{mg} \mathrm{F} \cdot \mathrm{kg}^{-1} \mathrm{~d}^{-1}\right)$. This is probably due to a higher consumption of water.

Teresina is a city that experiences high temperatures throughout the year and provides fluoridated water supply for collective use; thus, the greatest contribution to fluoride intake is from water, which is confirmed by Rodrigues et al. ${ }^{22}$ The observed value was similar to the findings of Omena et al., ${ }^{8}$ despite differences between the ambient temperatures in the three cities. Teresina is much warmer $\left(33.5^{\circ} \mathrm{C}\right.$ to $\left.24^{\circ} \mathrm{C}\right)$ and the fluoride concentration of the public water supply is lower ( 0.6 vs. $0.94 \mathrm{mg} / \mathrm{ml})$. These factors may explain the similarities among studies.

The fluoride intake from toothpaste was $0.010 \mathrm{mg}$ $\mathrm{F} \cdot \mathrm{kg}^{-1} \mathrm{~d}^{-1}$. This result is in disagreement with other studies conducted in Northeastern Brazil ${ }^{8,10}$ as well as in other Brazilian regions, ${ }^{6,18,19,23,24}$ where higher values were observed. In the present study, flavored toothpaste was the most frequently used and almost all children brushed at least twice a day, factors that have been cited in the literature as associated with the risk of fluorosis. ${ }^{23}$ However, tooth brushing was performed in the majority of cases by a caregiver, which explains the smaller amount of toothpaste used in comparison to other studies. ${ }^{6,17,19}$ In our study, fluoride dosage was calculated by the TSF method rather than considering the concentration indicated on the toothpaste label. Moreover, our participants had in general a high socioeconomic status and were consequently more informed about oral health care and the risk of using excess toothpaste. This sample was chosen for having a diversified diet, free access to water, and an easy diet collection at home.

The largest amounts of fluoride ingested by children during tooth brushing were observed in those who used flavored toothpaste, in agreement with the observations of Kobayashi et al. ${ }^{25}$ and Oliveira et al. ${ }^{20}$. The average concentration of fluoride of these toothpastes was 1,100 ppm.

In this study, water was the greater contributor to total fluoride intake, followed by toothpaste, other beverages, and solid foods, resulting in significant differences between sources. In other studies, ${ }^{6,8,18,23,26,27,28}$ toothpaste was the main source of fluoride intake.

Teresina has no fixed system for water fluoridation. A research conducted in 2001 showed concentrations ranging from 0.8 to $0.9 \mathrm{ppm} \mathrm{F}^{12}$ in different months. However, a recent control (2012) showed that the averages were closer to $0.6 \mathrm{ppm} \mathrm{F}^{29}$ as was observed in this study. This value proved to be safe with regard to ingestion by children and may have contributed to caries control. According to the latest national 
epidemiological survey, the mean DMFT (number of decayed, missing, and filled teeth) in children up to 12 years of age in Teresina was 1.5, which is lower than the national average (2.1) and other cities in Northeastern Brazil that do not have fluoridated water. ${ }^{30}$ Although the average fluoride intake was low, probably due to the low ingestion of toothpaste, some children exceeded the safety threshold. One way to reduce the intake of fluoride from toothpaste is through the orientation on the needed amount of toothpaste to be placed on the brush and parent supervision when brushing, ${ }^{20,26}$ to prevent children from swallowing. Moreover, it is important to periodically control the fluoridation of the public water supply.

In this study, diet was the greatest source of fluoride (more precisely from water), differing from Lima et. al. ${ }^{10}$, who found that dentifrice was the largest source in a sample of the same city. A study is therefore needed to assess the total fluoride intake in children of low socioeconomic status, as they may be exposed to higher levels of fluoride.

One of the limitations of this study was that it was performed on two non-consecutive days, with an interval of two months between each collection, unlike other studies that collected data on two consecutive days ${ }^{6,10,18,22}$ to improve the accuracy of

\section{References}

1. Petersen PE, Bourgeois D, Ogawa H, Estupinan-Day S, Ndiaye $C$. The global burden of oral diseases and risks to oral health. Bull World Health Organ. 2005 Sep;83(9):661-9. https://doi.org/S0042-96862005000900011

2. Iheozor-Ejiofor Z, Worthington HV, Walsh T, O'Malley L, Clarkson $J E$, Macey R et al. Water fluoridation for the prevention of dental caries. Cochrane Database Syst Rev. 2015 Jun;(6):CD010856. https://doi.org/10.1002/14651858.CD010856.pub2

3. Cury JA, Tenuta LM. How to maintain a cariostatic fluoride concentration in the oral environment. Adv Dent Res. 2008 Jul;20(1):13-6. https://doi.org/10.1177/154407370802000104

4. Levy SM, Broffitt B, Marshall TA, Eichenberger-Gilmore JM, Warren JJ. Associations between fluorosis of permanent incisors and fluoride intake from infant formula, other dietary sources and dentifrice during early childhood. J Am Dent Assoc. 2010 Oct;141(10):1190-201.

https://doi.org/10.14219/jada.archive.2010.0046 the information. An attempt to reduce this limitation was made by collecting food samples on days that parents were at home, as was done in the study by Oganessian et al. ${ }^{31}$ Another advantage is diet stability, since on consecutive days the type of food eaten can be similar. An additional limitation is that the duplicate diet was collected by the caregiver. To minimize this limitation, verbal and written instructions were given on how the collection should be performed. In addition, the high education level of the parents contributed to the methodology be followed more precisely.

In conclusion, most of the evaluated children from a tropical semi-arid municipality of high temperatures and a fluoridated public water supply had low fluoride intake from diet and toothpaste; water had the greatest contribution in fluoride intake.

\section{Acknowledgements}

This research was funded by the National Council for Scientific and Technological Development (CNPq, no. 403238/2012-9), which had no role in the study design, data collection, analysis, publication decisions or preparation of the manuscript.

We thank all participants and caretakers for their collaboration during the study.
5. Burt BA. The changing patterns of systemic fluoride intake. J Dent Res. 1992 May;71(5):1228-37. https://doi.org/10.1177/00220345920710051601

6. Lima YB, Cury JA. [Fluoride intake by children from water and dentifrice]. Rev Saude Publica. 2001 Dec;35(6):576-81. Portuguese. https://doi.org/10.1590/S0034-89102001000600012

7. Lima YB, Cury JA. Seasonal variation of fluoride intake by children in a subtropical region. Caries Res. 2003 Sep-Oct;37(5):335-8. https://doi.org/10.1159/000072164

8. Omena LM, Silva MF, Pinheiro CC, Cavalcante JC, Sampaio FC. Fluoride intake from drinking water and dentifrice by children living in a tropical area of Brazil. J Appl Oral Sci. 2006 Oct;14(5):382-7. https://doi.org/10.1590/S1678-77572006000500015

9. Buzalaf MA, Rodrigues MH, Pessan JP, Leite AL, Arana A, Villena RS et al. Biomarkers of fluoride in children exposed to different sources of systemic fluoride. J Dent Res. 2011 Feb;90(2):215-9. https://doi.org/10.1177/0022034510385937 
10. Lima CV, Cury JA, Vale GC, Lima MD, Moura LF, Moura MS. Total Fluoride Intake by Children from a Tropical Brazilian City. Caries Res. 2015;49(6):640-6. https://doi.org/10.1159/000442029

11. Moura MS, Barbosa PR, Nunes-Dos-Santos DL, Dantas-Neta NB, Moura LF, de Lima MD. [Epidemiological surveillance of dental fluorosis in a city with a tropical climate with a fluoridated public drinking water supply]. Cien Saúde Colet. 2016 Apr;21(4):1247-54. Portuguese. https://doi.org/10.1590/1413-81232015214.13852015

12. Moura MS, Silva JS, Simplício AH, Cury JA. [Long-term assessment of fluoride level of public water supply in TeresinaPiauí]. Rev Odonto Ciênc. 2005;20(48):132-6. Portuguese.

13. Mascarenhas AK, Burt BA. Fluorosis risk from early exposure to fluoride toothpaste. Community Dent Oral Epidemiol. 1998 Aug;26(4):241-8. https://doi.org/10.1111/j.1600-0528.1998.tb01957.x

14. Hong L, Levy SM, Broffitt B, Warren JJ, Kanellis MJ, Wefel JS et al. Timing of fluoride intake in relation to development of fluorosis on maxillary central incisors. Community Dent Oral Epidemiol. 2006a Aug;34(4):299-309. https://doi.org/10.1111/j.1600-0528.2006.00281.x

15. Hong L, Levy SM, Warren JJ, Broffitt B, Cavanaugh J. Fluoride intake levels in relation to fluorosis development in permanent maxillary central incisors and first molars. Caries Res. 2006b;40(6):494-500. https://doi.org/10.1159/000095648

16. Armitage P, Berry G. Statistical methods in medical research. 3rd ed. Boston: Blackwell; 1994.

17. Guha-Chowdhury N, Drummond BK, Smillie AC. Total fluoride intake in children aged 3 to 4 years-a longitudinal study. J Dent Res. 1996 Jul;75(7):1451-7. https://doi.org/10.1177/00220345960750070401

18. Paiva SM, Lima YB, Cury JA. Fluoride intake by Brazilian children from two communities with fluoridated water. Community Dent Oral Epidemiol. 2003 Jun;31(3):184-91. https://doi.org/10.1034/j.1600-0528.2003.00035.x

19. Martins CC, Oliveira MJ, Pordeus IA, Cury JA, Paiva SM. Association between socioeconomic factors and the choice of dentifrice and fluoride intake by children. Int J Environ Res Public Health. 2011 Nov;8(11):4284-99. https://doi.org/10.3390/ijerph8114284

20. Oliveira MJL, Paiva SM, Martins LHPM, Ramos-Jorge ML, Lima YBO, Cury JA. Fluoride intake by children at risk for the development of dental fluorosis: comparison of regular toothpastes and flavoured toothpastes for children. Caries Res. 2007;41(6):460-6. https://doi.org/10.1159/000107933

21. Oliveira MJ, Martins CC, Paiva SM, Tenuta LM, Cury JA. Estimated fluoride doses from toothpastes should be based on total soluble fluoride. Int J Environ Res Public Health. 2013 Nov; 10(11):5726-36. https://doi.org/10.3390/ijerph10115726

22. Rodrigues MH, Leite AL, Arana A, Villena RS, Forte FD, Sampaio FC et al. Dietary fluoride intake by children receiving different sources of systemic fluoride. J Dent Res. 2009 Feb;88(2):142-5. https://doi.org/10.1177/0022034508328426

23. Almeida BS, Cardoso VES, Buzalaf MA. Fluoride ingestion from toothpaste and diet in 1- to 3-year-old Brazilian children. Community Dent Oral Epidemiol. 2007 Feb;35(1):53-63. https://doi.org/10.1111/j.1600-0528.2007.00328.x

24. Nascimento HA, Ferreira JMS, Granville-Garcia AF, Costa EMB, Cavalcante ALA, Sampaio FC. Estimation of toothpaste fluoride intake in preschool children. Braz Dent J. 2013;24(2):142-6. https://doi.org/10.1590/0103-6440201302087

25. Kobayashi CA, Belini MR, Italiani FM, Pauleto AR, Araúio JJ, Tessarolli $V$ et al. Factors influencing fluoride ingestion from dentifrice by children. Community Dent Oral Epidemiol. 2011 Oct;39(5):426-32. https://doi.org/10.1111/i.1600-0528.2011.00615.x

26. Miziara AP, Philippi ST, Levy FM, Buzalaf MA. Fluoride ingestion from food items and dentifrice in 2-6-year-old Brazilian children living in a fluoridated area using a semiquantitative food frequency questionnaire. Community Dent Oral Epidemiol. 2009 Aug;37(4):305-15. https://doi.org/10.1111/j.1600-0528.2009.00477.x

27. Levy FM, Olympio KP, Philippi ST, Buzalaf MA. Fluoride intake from food items in 2- to 6-year-old Brazilian children living in a non-fluoridated area using a semiquantitative food frequency questionnaire. Int J Paediatr Dent. 2013 Nov;23(6):444-51. https://doi.org/10.1111/ipd.12015

28. Martínez-Mier EA, Soto-Rojas AE, Ureña-Cirett JL, Stookey GK, Dunipace AJ. Fluoride intake from foods, beverages and dentifrice by children in Mexico. Community Dent Oral Epidemiol. 2003 Jun;31(3):221-30. https://doi.org/10.1034/i.1600-0528.2003.00043.x

29. Matos CV, Barros HL, Simplício AH, Moura LF, Sousa-Nétto OB, Moura MS. Heterocontrole da fluoretação das águas de abastecimento público na cidade de Teresina, Piauí, Brasil. Pesqui Bras Odontopediatria Clin Integr. 2011;11:36.

30. Ministério da Saúde (BR). Pesquisa Nacional de Saúde Bucal - SB Brasil 2010: resultados principais. Brasília, FG: Ministério da Saúde; 2011.

31. Oganessian E, Ivancakova R, Lencova E, Broukal Z. Alimentary fluoride intake in preschool children. BMC Public Health. 2011 Oct;11(1):768. https://doi.org/10.1186/1471-2458-11-768 